\title{
Balancing continuity and novelty: The practical relevance of management research from the practitioners' perspective
}

Splitter, Violetta

\begin{abstract}
In management research, the literature on practical relevance holds that practitioners actively construct practical relevance. However, the practitioners' perspective on relevance has received very little scholarly attention to date. This paper puts forward a theoretical model for examining how practitioners construct academic knowledge as practically relevant based on interviews with practitioners enrolled on executive MBA (EMBA) courses. The model shows that practitioners construct academic knowledge as relevant by (1) perceiving it as congruent with their context, experiences and intuition, (2) extending their knowledge by new instruments, constructs, and means of scientific framing and (3) reconnecting it to their contexts and professional practices. This model extends the literature by showing that, in order to be considered practically relevant, academic knowledge needs to balance novelty and continuity. Additionally, the paper shows that practitioners are unlikely to perceive as relevant ambiguous academic knowledge that is 'action expansive', i.e. that presents them with an overwhelming range of possible actions.
\end{abstract}

DOI: https://doi.org/10.31235/osf.io/v4su8

Posted at the Zurich Open Repository and Archive, University of Zurich

ZORA URL: https://doi.org/10.5167/uzh-172963

Conference or Workshop Item

Published Version

Originally published at:

Splitter, Violetta (2018). Balancing continuity and novelty: The practical relevance of management research from the practitioners' perspective. In: TOPOS Seminar, University of Oxford, 27 February 2018.

DOI: https://doi.org/10.31235/osf.io/v4su8 


\title{
Balancing continuity and novelty: The practical relevance of management research from the practitioners' perspective
}

\author{
Violetta Splitter \\ University of Zurich \\ Chair of Organization and Management \\ Phone: +4176 7342027 \\ Universitaetstrasse 84 \\ $\mathrm{CH}-8006$ Zurich \\ violetta.splitter@uzh.ch
}

\begin{abstract}
In management research, the literature on practical relevance holds that practitioners actively construct practical relevance. However, the practitioners' perspective on relevance has received very little scholarly attention to date. This paper puts forward a theoretical model for examining how practitioners construct academic knowledge as practically relevant based on interviews with practitioners enrolled on executive MBA (EMBA) courses. The model shows that practitioners construct academic knowledge as relevant by (1) perceiving it as congruent with their context, experiences and intuition, (2) extending their knowledge by new instruments, constructs, and means of scientific framing and (3) reconnecting it to their contexts and professional practices. This model extends the literature by showing that, in order to be considered practically relevant, academic knowledge needs to balance novelty and continuity. Additionally, the paper shows that practitioners are unlikely to perceive as relevant ambiguous academic knowledge that is 'action expansive', i.e. that presents them with an overwhelming range of possible actions.
\end{abstract}

\section{Keywords}

Ambiguity, academic knowledge, construction of relevance, practical relevance, practitioners' perspective 


\section{Introduction}

Understanding how management research can achieve practical relevance is central to research on management as an applied science. To date, much of the literature focuses mainly on how practical relevance can be achieved from a scholarly point of view. The underlying assumption is that academic knowledge that is adequately produced (Gibbons et al., 1994; Greenwood, Suddaby, \& Hinings, 2002; Reason, 2006; Rousseau, 2012; Van de Ven \& Johnson, 2006) and disseminated (Bansal, et al., 2012; Gopinath \& Hoffman, 1995; Oviatt \& Miller, 1989; Starkey \& Madan, 2001) will become relevant. Most studies in this literature 'rely (implicitly or explicitly) on models based on the problematic notion of a simple and linear transfer of knowledge, [even though] these models cannot capture adequately the complexities of the utilization process' (Kieser, Nicolai, \& Seidl, 2015, p. 72).

A few studies, however, acknowledge these complexities by arguing that practitioners are constitutive in the construction of relevance ( Benders \& Van Ven, 1997; Nicolai \& Dautwiz, 2010; Rasche \& Behnam, 2009; Seidl, 2007). Accordingly, they define practical relevance in terms of research that 'leads to the change, modification, or confirmation of how managers think, talk and act' (Kieser, Nicolai, \& Seidl, 2015, p. 144). These studies stress that the 'consumers' of knowledge - the practitioners - actively construct academic knowledge as practically relevant according to their own contexts and existing knowledge (Nicolai \& Dautwiz, 2010; Rasche \& Behnam, 2009). Furthermore they argue that ambiguous academic knowledge can be adapted more easily to practical contexts (Astely \& Zammuto, 1992; Benders \& Van Ven, 1997). Although these studies stress that management science cannot define a priori what is relevant but practitioners themselves ultimately determine relevance, we know very little how practitioners construct academic knowledge as practically relevant. In particular, understanding how relevance is constructed from the practitioners' perspective would allow scholars to produce knowledge that is more likely to be practically relevant by 
considering the 'dynamics between academic and practical or experiential knowledge' (Kieser, Nicolai, \& Seidl, 2015, p. 71) and the different forms of relevance that these dynamics entail (Nicolai \& Seidl, 2010). Thus, this study responds to the call for empirical, theory-building research on the connection between the results of scientific research and management practice (Augier \& March, 2011; Bartunek \& Rynes, 2014; Corley \& Gioia, 2011; Wensley, 2007).

To examine the practitioners' perspective on relevance this paper builds on 53 semi-structured interviews during which practitioners evaluated the relevance of academic concepts they had encountered while attending an executive MBA (EMBA) course. Based on the analysis of practitioners' individual interpretations of the relevance or irrelevance of academic concepts, the paper shows that the practitioners construct academic knowledge as relevant by (1) perceiving it as congruent with their context, experiences and intuition, (2) extending their knowledge by new instruments, constructs, and means of scientific framing and (3) reconnecting the novel knowledge to their professional practices and contexts. In addition, this study shows that practitioners' relevance construction is mediated by the mechanisms of expansive and restrictive ambiguity. Through these mechanisms, ambiguous knowledge enables practitioners to expand, but in certain cases also limits practitioners' relevance construction.

The study contributes to the literature in two ways. First, it shows that academic knowledge must be familiar enough to its consumers so that they can recognise it as congruent with their experiences and 'match' it to various practical issues, and at the same time novel enough to extend their own knowledge. The patterns of 'congruence recognition' and 'knowledge extension' demand that academic knowledge balance continuity and novelty in order to be practically relevant. Second, this study shows that ambiguous academic knowledge that is 'action expansive', i.e. that points to multiple courses of action might overwhelm practitioners 
and make it hard for them to choose the course of action that is most meaningful to them. In such cases, the relevance of ambiguous academic knowledge is limited.

\section{Theoretical background}

Management research frequently emphasizes its status as an applied science. As a result, there is a vast body of literature representing a variety of perspectives on how relevance is achieved. According to the most prevalent perspectives, adequately produced (Gibbons et al., 1994; Greenwood, Suddaby, \& Hinings, 2002; Reason, 2006; Rousseau, 2012; Van de Ven \& Johnson, 2006) and disseminated (Bansal, et al., 2012; Gopinath \& Hoffman, 1995; Oviatt \& Miller, 1989; Starkey \& Madan, 2001) academic knowledge will become relevant. Two perspectives, however, have challenged the fundamental assumption that practical relevance is defined from a scholarly point of view.

The first perspective concerns the adoption of academic knowledge to practice. According to this perspective, academic management knowledge can be defined as a body of statements for which there are explanations that management scientists have methodologically approved (Schreyogg \& Geiger, 2003). This conceptualization of (academic and other) knowledge is based on the premise that the context in which knowledge is embedded plays a crucial role in how it is interpreted (Brown \& Duguid, 1991), 'which means that knowledge cannot be considered independently of its context' (Kieser, Nicolai, \& Seidl, 2015, p. 73; see also Bartunek \& Reynes, 2014; Corley \& Gioia, 2011). From this perspective, it is not possible to transfer knowledge directly from management science to practice. Nevertheless, academic knowledge can generate 'productive misunderstandings' (Seidl, 2007, p. 206) or 'fictions' (Rasche \& Behnam, 2009, p. 244). 'Productive misunderstanding' arise because practice cannot but reconstruct the meaning of academic knowledge in its own terms and context and 'at the same time $[\ldots]$ make use of the meaning material $[\ldots]$ as an external provocation to create internally something new' (Teubner, 2000, p. 48, cited in Seidl, 2007, p. 207). 
Consequently, the meaning of research content changes when practitioners adapt it to their context (Jarzabkowski \& Wilson, 2006; Nicolai \& Dautwitz, 2010; Seidl, 2007, 2009). The context into which research results become embedded 'restricts the range of possible meanings that [one] may attach to them' (Seidl, 2007, p. 207). In this sense, academic knowledge is relevant only if it resonates in a meaningful way with the assumptions (Corburn, 2005) or experience and interests of practitioners (Nicolai \& Dautwitz, 2010), and generally with the context to which it is adapted (Seidl, 2007).

By contrast, 'fictions' indicates that practitioners act as if academic knowledge were relevant before they apply it. Academic knowledge is

usually formulated at such a high level of generality that in the moment of application the relevance of research is still a fiction: Managers do not and cannot know yet whether knowledge is relevant; however, they can act as if the offered knowledge were relevant (Rasche \& Behnam, 2009, p. 249).

Both productive misunderstandings and fictions can be viewed as 'perturbations' to the practice from which further 'sensemaking processes can unfold' (Rasche \& Behnam, 2009, p. 250). In other words, these perturbations are modified, supplemented or ignored, depending on the context and on individual interests and experiences. Thus, the particular ways in which academic knowledge is relevant to practice and understood by practitioners is an active process that is determined by the domain of practice itself (Kieser, Nicolai, \& Seidl, 2015).

Another perspective focuses on how the ambiguity of academic knowledge affects its practical relevance. Related studies argue that ambiguous knowledge is more likely to be practically relevant than unambiguous knowledge because its 'openness of meaning' (Powell, Lovallo, \& Caringal, 2006, p. 175) and 'interpretive viability' (Benders \& Bijsterfeld, 2000, p. 50), leave room for interpretation in ways that are relevant to the interests of disparate groups of people (Astley \& Zammuto, 1992). This view contrasts with the argument that the 
findings of academic research are irrelevant to practice because they are vaguely worded (MacLean, MacIntosh, \& Grant, 2002; Sandelands \& Drazin, 1989) and neither address concrete practical problems nor provide context-specific knowledge (Hambrick, 1994; Hinings \& Greenwood, 2002; Huff \& Huff, 2001; Van de Ven \& Johnson, 2006). The proponents of ambiguity argue that although ambiguity

entails a loss of directly descriptive information and fails to capture the richness and complexity of phenomena encountered by practitioners in organizational settings $[\ldots]$ it enhances its capacity to convey meaningful connotations $[\ldots]$. The reduction of theoretical language to highly specific, empirically descriptive terminology would destroy this source of meaning. (Astley \& Zammuto, 1992, p. 445)

In this view, ambiguous scientific concepts speak 'to different audiences, allowing each subgroup to interpret the theory in congenial, if mutually incompatible, ways' (Davis, 1986, p. 296), such that 'multiple audiences can each construct a meaning of the concept that is beneficial to their interests' (Benders \& van Veen, 2001, p. 38).

Most studies that examine the role of ambiguity in achieving relevance thus assume that ambiguous academic knowledge facilitates practitioners' construction of relevance. However, these studies do not discuss how practitioners construct the ambiguity of academic concepts as an opportunity to 'contextualize this knowledge' (Rasche \& Behnam, 2009, p. 252; see also Ortmann \& Salzman, 2002). Overall, both perspectives consider the constitutive role of the practitioner in constructing relevance. However, the particular ways in which practitioners construct academic knowledge in general, and ambiguous academic knowledge in particular, as relevant has not been systematically examined. Against this background, this paper focuses on the following research question: How do practitioners construct (ambiguous) academic knowledge as practically relevant? 


\section{Methodology}

\section{Research context}

This study will examine how practitioners construct academic knowledge as relevant in the context of executive management education. This context is particularly suitable for several reasons. First, as the AACSB states, 'the most obvious way that faculty research impacts practice is through education' (AACSB International, Impact of Research Task Force, 2007, p. 37). Second, because the purpose of the academic knowledge that executive courses provide is to help practitioners identify and assess appropriate interventions in response to managerial challenges (Burke \& Rau, 2010; Vaara \& Faÿ, 2012). For that reason, this context lends itself to examining how practitioners evaluate the relevance of academic knowledge. Third, because EMBA courses are primarily targeted at executives with several years of professional or managerial experience (Conger \& Xin, 2000; Vaara \& Faÿ, 2012), which allows them to judge whether academic knowledge might be of relevance to their professional contexts. Fourth, because executive courses are typically conceptualized as a setting in which practitioners can connect management research to their own managerial experiences (Anderson, 2002; Conger \& Xin, 2000; Tushman, et al., 2007), they are a suitable context for studying how practitioners construct academic knowledge as relevant in light of their individual experiences.

\section{Data collection}

This study draws on data collected from a sample of 121 EMBA students in the executive programmes of four European universities, which were chosen by four criteria. First, the selected programmes obtain at least three accreditations recognized by the following bodies: Association to Advance Collegiate Schools of Business (AACSB), European Quality Improvement System (EQUIS), Association of MBAs (AMBA), Quality Assurance Agency for Higher Education (QAA), and Foundation for International Business Administration Accreditation (FIBAA). This ensures the integration of 'high-quality' research in these 
programmes (Adler \& Harzing, 2009). Second, all courses relate to strategy, which are considered 'capstone' courses that integrate various areas of management (Baldridge, Floyd, \& Markóczy, 2004; Bower, 2008; Grant, 2008). Strategy courses are thus representative of management education compared to discipline-based or 'functional' courses (Goshal \& Moran, 1996; Jarzabkowski \& Whittington, 2008; Whittington, 2003). Furthermore, I assumed that I can meaningfully compare the perceptions of practitioners attending courses in the same subject, because they provide similar concepts. Third, the selected courses meet the criteria of heterogeneous sampling (Yin, 2013; Patton, 1990). As Table I shows, all courses employ a mixture of teaching methods, including lectures, case studies, group presentations, and real-life cases. These different teaching methods imply that practitioners learned academic knowledge in different ways, such as through reading academic articles, discussions in class, formal individual assignments (on the application of academic knowledge) or working on case studies in groups. The heterogeneity of the teaching methods counteracts the potential influence that a particular teaching method might have on how the practitioners construct relevance (Eisenhardt, 1991) and facilitates comparisons between the ways practitioners approach relevance across all courses.

\section{INSERT TABLE I ABOUT HERE}

Although each course uses a different teaching method, in all four cases the same academic concepts serve as a basis for theory-based strategy teaching. The similarity of the academic orientation in these courses is reflected in the reading material, syllabi, course announcements in the EMBA brochures (see also Table I).

As Table II shows, the students of each EMBA cohort were selected on the basis of their former education, professional experience (at least five years), current position (lower and 
middle managers as well as members of the TMT and CEOs) and the type of organization with which they were affiliated at the time, ranging from for-profit to non-profit and from large global firms to small regional firms. I purposely selected practitioners who used diverse frames of references to evaluate the relevance of academic knowledge so that the findings could be generalized to a wide variety of professional contexts.

\section{INSERT TABLE II ABOUT HERE}

I chose a qualitative research design (Langley \& Abdallah, 2011; Patton, 2005), which is well suited to the study of social constructions, such as the construction of relevance, especially when they refer to individuals' interpretations (Silverman, 2006; Maitlis, 2005). The advantage of a qualitative method is that informants act and talk in a natural way that is meaningful and culturally salient, which allows for rich and explanatory data (Langley, 1999; Huberman \& Miles, 2002).

\section{INSERT TABLE III ABOUT HERE}

As indicated in Table III, the main sources of data are 53 semi-structured interviews that typically lasted between half an hour and an hour and were conducted in my native language or in English. Most interviews were conducted after the end of the course or up to two weeks after the course and were based on a semi-structured interview schedule (see Appendix 1). I used a consistent set of prompts (but not specific content/concepts in order to avoid social desirability; cf. Butler, 1991) to elicit detailed responses on the practitioners' expectations and benefits regarding the course content (Gioia \& Thomas, 1996). The interviewees were asked to describe how they evaluated their course content and give examples that illustrated their 
evaluations. This prompted them to share 'stories' about various events and activities that contextualized their evaluations of academic knowledge (Eisenhardt \& Graebner, 2007; Langley et al., 2013; Rouleau, 2005). Sharing these stories also allowed the interviewees to critically reflect on the academic knowledge and its expected applicability.

To counteract the potential bias that might result from relying solely on how the interviewees perceived the relevance of the academic content (Denzin \& Lincoln, 2008; Eisenhardt, 1989) and to gather sufficiently broad information in order to develop a relatively holistic picture of the construction of relevance (Corbin \& Strauss, 2014), I probed the main data with secondary data. Including these secondary data also allowed me to gain an idea of how the EMBA students who were not interviewed perceived the relevance of their course content. This data included recorded field notes of 190 hours of non-participant observation of the practitioners' reactions and interactions during course-related activities, as well as slides, articles, (text)books, evaluations of the courses and notes and summaries taken by the interviewees and their fellow students (see Table I for an overview of all collected data).

\section{Data analysis}

To analyse the data, I used an iterative approach, circulating back and forth between the empirical material and the literature (Huberman \& Miles, 1994). The analysis proceeded in three main stages. In the first stage, I used qualitative content analysis to code all interviews per course (Langley \& Abdallah, 2011; Maitlis, 2005), focusing on how the interviewees constructed the relevance of the academic course content. To cross-check and complement the interviewees' accounts, I also drew on my field notes, the practitioners' notes and summaries as well as slides and texts used in class.

I identified the interviewees' accounts as constructions of relevance when they described how they viewed or understood the relevance of an academic concept; i.e., when they mentioned that the concept would be 'relevant', 'useful', 'helpful' - or, conversely, 'not helpful', 'not 
applicable' or 'not useful' - in leading to 'a change, modification or confirmation of how they think, talk and act' (Kieser, Nicolai, \& Seidl, 2015, p. 144; see also Nicolai \& Seidl, 2010). I then refined the coding according to different understandings of 'relevance': an academic concept was seen as 'relevant' (1) if the practitioner felt that it would improve existing professional practices (e.g., by enhancing a practitioner's communication or problem-solving capabilities) or the way a situation or problem was understood, (2) if the practitioner felt that it was innovative because it pointed to new courses of action, new ways of thinking or new ways of understanding a situation or problem, and (3) if it confirmed that past and prospective actions were appropriate, credible and thus legitimate. Once coding was complete, I discarded any accounts that depended on a particular teaching method (e.g., statements indicating that a concept was relevant because it was applied in a particular case-study) in order to identify how the interviewees perceived the relevance of the academic concepts regardless of how they were taught.

Following that, I went through the refined sample of accounts to identify the particular academic concepts to which each referred. For that purpose, I sought explicitly or implicitly mentioned concepts that could be related to the scientific discourse (Nicolai \& Dautwitz, 2010), such as 'core competence' (Prahalad \& Hamel, 1990), 'competitive advantage' (Barney, 1991), 'organizational design' (Donaldson, 2001), 'strategic issue management' (Ansoff, 1980), 'incentive systems' (Bebchuk \& Fried, 2006), 'non-market strategy' (Baron, 1995), 'creative destruction' (Schumpeter, 1950) and 'weak ties' (Granovetter, 1973).

In the second stage of the analysis I focused on identifying how practitioners construct relevance. First, through an inductive and recursive process I identified the first-order concepts (Van Maanen, 1979) $)^{\mathrm{i}}$ that described how practitioners construct the relevance on the basis of academic concepts. I began by examining the descriptions (mostly in terms of examples and stories) of the ways in which relevance was constructed in each account. 
Consulting the literature on the construction of relevance (Corburn, 2005; Nicolai \& Dautwitz, 2010; Nicolai \& Seidl, 2010), I coded all accounts according to how the interviewees constructed the relation between an academic concept and their own background, how they perceived a particular academic concept and how they constructed the relevance of this concept.

I considered an account to refer to the relation between a particular academic concept and practitioners' background in the following cases: when a concept was related to (1) practitioners' contexts, such as the type of industry, type and size of organization, or contextspecific values and expected behaviour associated, as well as the particular difficulties associated with these contexts, such as disruptive technologies, unproductive strategy meetings or a lack of identification with the corporate strategy, (2) practitioners' educational and professional experiences, i.e. (professional) knowledge he or she had accumulated (Hill \& Houghton, 2001; March, 2006), (3) practitioners' intuitions, i.e., hunches about specific solutions to specific problems that were based on 'life-learned rules and exceptions, dispositions and tendencies, balances and checks' (Minsky, 1988, p. 22; see also Polanyi \& Prosch, 1977). Practitioners' accounts were also coded as relations between a particular concept and practitioners' background if practitioners perceived that the concept contradicts their experiences and intuitions.

I considered an account to indicate how practitioners perceived a particular academic concept when it contained references to a type of new knowledge that this concept provided to them. These types of knowledge might be systematics of ordering (i.e. checklists, procedures and tools), ways of conceptualizing a situation, causal relations (between, e.g., a policy and an outcome) or scientific framing (i.e. a new scientific language). Finally, I coded how practitioners construct the relevance of a particular concept on the basis of different understandings of 'relevance' as improvement, innovation, or legitimization (identified in the 
first phase of the analysis). I then compared the codes to check for similarities and aggregated them to identify a set of first-order concepts.

To test inter-coder reliability and check for any inconsistencies in interpreting the data (Miles \& Huberman, 1994; Tinsley \& Weiss, 2000), I presented the concepts I had identified in the second stage of the analysis to two colleagues who were familiar with qualitative methods but were not involved in this study. For that purpose, I provided each coder with definitions of the concepts and asked them to sort about one third of the quotes corresponding to each course on the basis of the identified concepts. The average agreement level between each coder and the overall coding scheme was satisfactorily high at 85.0 per cent (Gioia, Corley, \& Hamilton, 2013). Disagreements in coding served as the basis for discussions about how to revise and strengthen the coding and thus improve the reliability of the interpretations. These discussions continued until a decision was reached about how to solve each discrepancy. In the final step of this stage in the analysis, I engaged in axial coding (Strauss \& Corbin, 1998) to build more abstract descriptions of how the practitioners constructed relevance and I combined a set of first-order concepts to construct a set of second-order themes (Corley \& Gioia, 2004).

In the third stage, I integrated the negative accounts I had identified in the first stage to counter-check the validity of the second-order themes. These checks revealed that if practitioners perceived academic concepts as ambiguous, they rejected these concepts as irrelevant. Drawing on studies examining the role of ambiguity in constructing relevance (Astley \& Zammuto, 1992; Benders \& van Veen, 2001), I identified first-order concepts that indicated how ambiguous concepts influenced the way in which practitioners constructed relevance. Academic concepts were coded as ambiguous if practitioners considered them as vaguely worded, abstract and general, variously interpretable, or variously usable (Astley \& Zammuto, 1992). Repeating the process of comparison and aggregation, I derived from the first-order concepts a second-order theme that indicates the connection between ambiguity 
and the construction of relevance. Figure 1 shows the overall data structure including the set of second-order themes and the first-order concepts from which they are derived.

INSERT FIGURE 1 ABOUT HERE

\section{Findings}

The analysis of the data revealed three patterns that explain how practitioners construct academic knowledge as relevant and two mechanisms through which ambiguous academic knowledge influences how practitioners construct the relevance of academic knowledge; all five are depicted in Figure 2. In the following I will discuss these findings along with illustrative quotes (Appendix 2 displays additional quotes together with the first-order concepts and the related second-order themes).

\section{INSERT FIGURE 2 ABOUT HERE}

\section{Patterns of constructing relevance}

The first pattern involves the recognition of congruence between academic knowledge and practitioner's context (theme 1), experience (theme 2) or intuition (theme 3). Through recognizing congruence practitioners make sense of an academic concept that they recognize as congruent with their contextual problems and needs, something they are experiencing/have experienced or with their intuitive understanding of something. This kind of congruence facilitates the construction of relevance. Appendix 2 provides representative quotes that illustrate each of these second-order themes and the related first-order concepts. 
The first theme, congruence with context, reflects how the practitioners identified in academic knowledge a potential solution to a specific (current or future) problem or need in their work context. The following quote, for example, illustrates how a marketing manager connected a concrete problem at her firm with Porter's concept of 'competitive strategy' (Porter, 1997), which is scientifically rooted in resource-based theory (Barney, 2001) and relates to Ansoff's terms of the "outside-in" and "inside-out view" of strategy (Ansoff, 1965).

In my firm, we are too concerned about ourselves, instead of being concerned about the customer [...]. The 'inside-out perspective is OK, but we also have to think about the environment. Thus 'outside-in' would be a necessary switch for us because new technologies change the behaviour of the consumer and this perspective (...) has not yet penetrated our work. (Marketing account manager of an insurance company)

The novel concepts prompted this manager to visualize 'a necessary switch' in perspective as a solution to the problem she describes.

Practitioners may also construct academic knowledge as relevant by recognizing congruence with their own experiences. Although there might be some overlap between the first and second themes, the second one (theme 2), congruence with experience, has to do with an individual's generalized experience, rather than with specific work-related experiences, such as a problem at work. In the following quote, for example, a marketing manager recognizes that his personal experience of working on a strategic issue is reflected in the scientific concept of means-ends introduced by Herbert Simon (1978).

The point is that you realize that every strategic issue that you add will have a follow-up element. That is cause-and-effect. Often in strategy you think about an issue but then you stop and you don't think about the next steps. So [the concept] provides relational and consequential thinking. (Marketing manager of a logistics company)

The third theme, congruence with intuition, reflects the fit between an academic concept and a practitioner's intuitive approach to, e.g., solving a problem or handling a relationship. The following quote, for example, illustrates that a patent attorney relates the scientific concept of 
emerging markets that Geroski (2003) developed to her own intuitive approach to analysing a nascent market.

The concept provided a methodological way of analysing the market and where we stand with innovation. [...] It probably would have been the way I analysed it had I not known this concept. [...] For instance, when you are examining a market, let's say a nascent market [...], I would have analysed the technology, I would have analysed the market and then analysed the organization. [However, without this concept] I might have just jumbled all those ideas into one unorganized thought. (Patent attorney)

Generally, by relating an academic concept to their specific context, to their general experience or to their intuition, practitioners construct it as relevant. By contrast, practitioners who find that an academic concept is not congruent with their experience or does not reflect their previous knowledge, do not construct it as relevant. The following quote is from the HR manager of a confectionery manufacturer who could not relate the academic concept of procedural justice, which was developed by Kim and Mauborgne (1995), to his experiences.

My experience is that it's not true that we (achieve a commitment) that quickly. So I'm struggling to agree with that. Because in my company, I know what will happen: The moment someone opens the mouth and says something, you have eight other people jump into it. So I struggle to see this procedural justice happening in practice.

The second pattern indicates that practitioners construct relevance by extending their background by novel knowledge. The pattern of knowledge extension allows practitioners to expand their knowledge by means of new academic knowledge. In this case, practitioners perceive the new knowledge as an instrument (theme 4), construct (theme 5), or a means of scientific framing (theme 6). These second-order themes and the first-order concepts from which they derive are illustrated in Appendix 2.

Practitioners who construct academic knowledge as an instrument (theme 4) perceive scientific concepts as new procedures or systematics for ordering ideas or as tools. The following example illustrates how a general manager constructed the academic concept of 
strategic issue management (Ansoff, 1980) as a new reflective procedure, which extended his intuitive way of understanding strategy.

[Strategic issue management] provides a core reflection tool. You're talking about strategic issues that are more or less intuitive and common sense but you're trying to get systematic about your insights and this methodical reflection helps you to get your strategic issues done in a more systematic way.

Practitioners can also extend their knowledge by means of new constructs (theme 5), i.e., new conceptualizations or causal relations that stem from academic knowledge. The next quote, for example, shows that the CEO of a sugar cane factory took up the concept of non-market strategy, which was introduced by Baron (1995) and further developed by Geroski (2003). He perceives this concept as a new construct, which extended his previous knowledge of company internationalization.

The market strategy was very important when our Australian company diversified to Switzerland. [...] We were focusing on competitors, the suppliers, the drivers and the bargaining power and so forth. But through this stack of insight [...], we began to diversify our attention to non-market. [This implied], building relationships in Switzerland, for example with some official bureaucrats, and [with] the media [...] and the NGOs. [...] The non-market side of the business [...] really opened [an area to which] we were never exposed.

By using scientific language or jargon practitioners extend their knowledge by a new scientific framing (theme 6). As the following quote shows, the marketing account manager of an insurance company found that the terminology associated with the concept of strategic issue management (Ansoff, 1980) extended her experiences with developing strategy.

Overall, I got a better understanding of how a strategy is developed in our firm and that it follows exactly the procedure [prescribed by the concept of strategic issue management]. And now I have a name for that.

Practitioners can also extend their existing knowledge by constructing different kinds of new knowledge based on a single academic concept. The following quote, for example, illustrates how the concept of emerging markets, developed by Geroski (2003), served both as a new 
construct and as a form of scientific framing that extended this patent attorney's intuitive understanding of this type of market.

I would say that it reaffirmed my intuitive way to look at a market [...]But I wouldn't have called it emerging markets. I wouldn't have used this name, and I hadn't been able to point to a diagram like the $S$-curve, [which shows] that technology can advance exponentially.

In contrast, practitioners who do not perceive an academic concept as novel knowledge that extends their intuition or existing knowledge construct it as irrelevant. In the next quote, for example, the $\mathrm{CCO}$ of a pharmaceutical company explains that the concept of absorptive capacity (Cohen \& Levinthal, 1990) is congruent with her existing knowledge and so does not allow her to extend her knowledge.

I didn't learn new things. [...] For example, 'absorptive capacity': I knew what this is about [...] but do I need this? I don't know. [...] So I wouldn't say that now I've got additional insights that I can apply [...] to my occupational context.

This quote illustrates that although practitioners may recognise an academic concept as congruent with what they know and what they have experienced, if this concept does not add something new to what they already know, it will not extend their knowledge.

The third pattern through which practitioners construct relevance involves reconnecting newly acquired knowledge to their professional contexts, experiences s well as intuitions. Through this pattern of reconnection, practitioners legitimize their actions (theme 7), envision improvement of their practices and their understanding of particular issues (theme 8) and come up with a new understanding of an issue or a new ways of approaching an issue (theme 9). Appendix 2 provides representative quotes that illustrate each of these second-order themes and the related first-order concepts.

More specifically, practitioners reconnect new academic knowledge (instruments, constructs and/or scientific framing) to an argument or course of action they seek to justify (theme 7). In that respect, the mechanism of reconnection enables them to legitimize or affirm a view, 
decision or action. The next quote illustrates how the concept of core competences (Prahalad \& Hamel, 1990) enabled the marketing account manager of an insurance company to extend her knowledge by a new construct (to understand better the factors the determine a firm's success). By reconnecting this new construct to her 'current situation' the concept allows her to justify her decisions to her boss.

I've learned that the positioning of a firm alone is not sufficient for success, but [a firm has] to gain advantage through the elements of skills, competences and resources. This helps me in my current situation, with the limited resources on the one hand, and the increasing sales figures on the other hand to explain my decisions to my boss and my team.

Practitioners can also use new academic knowledge to refine and improve existing professional practices, organizational processes or their general understanding of a particular situation (theme 8); in other words, reconnecting new knowledge to their context allows them to apply it in novel ways. The following quote shows that the scientific concept of transitional objects, which was developed by De Geus (1988), revealed a new procedure to develop strategy to the $\mathrm{CIO}$ of a telecommunication company. Reconnecting this new procedure to his experiences enabled him to improve the 'social aspects' of strategy development.

I liked the concept of transitional object. Usually the CFO or CEO says something that he always says [which results in] repeating every year the same. If you apply this concept, this does not work anymore. The process restrains you from having empty platitudes in your strategy and that these platitudes show up in the goals and the priorities. The process forces you to get out of your comfort zone. [This way] the process better manages social aspects and it helps me to better develop a strategy.

Through the pattern of reconnecting, practitioners can also detect improvements of their practices and understandings of an issue by relating new scientific framing to their contexts and previous knowledge. Typically, reconnecting scientific framing to their contexts and knowledge is considered relevant because it confirms or legitimizes courses of action. However, in some cases, it can also allow practitioners to improve their practices and understandings of an issue. For example, quote 8.1 (see Table IV) shows how the concept of 
absorptive capacity (Cohen \& Levinthal, 1990), provided a novel means of scientific framing to the $\mathrm{COO}$ of an international airline. By reconnecting the new knowledge to an existing practice, she will be able to communicate better with the CEO.

The new ways in which practitioners reconnect to their context novel knowledge that serves as an instrument, construct or form of scientific framing also allows them to approach various problems from a fresh perspective and devise innovative courses of action (theme 9). In contrast to improvement (theme 8), which relates to a refinement of existing courses of action and understandings of issues, this theme refers to new ways of thinking or alternative routes of action (with regard to already existing practices and ways of thinking). The following quote shows how the director of a sugar cane factory reconnected the 'new insights' he gained from the concept of market strategy (Geroski, 2003) to his experience with developing strategy, which allowed him to come up with a new approach to this issue (to diversify to non-market).

We have learned the concept of market strategy [...]. Through this stack of insights [...], we [my company] began to diversify our attention to non-market. [For example, we started] building relationships, which [is important if you do business in] Switzerland, [with] some official bureaucrats and [we started thinking about]what part the media is going to play and the NGOs.

The data also showed that there can be an overlap between different themes - for example, a new academic concept may be constructed as relevant because it allows a practitioner both to improve an existing approach to a problem and to devise an innovative way of dealing with this problem. The following quote illustrates this overlap: an IT analyst at an international bank refers to the scientific concept of strategic issue management (Ansoff, 1980) that she relates to the problems of implementing a corporate strategy in the her IT department.

\section{(...) there is a big gap in our corporate strategy and our business unit strategy}


By extending her view on her contextual problems, the concept is considered as a potential solution to this problem in the form of a procedure (instrument).

So what the process helps me is (...) to better understand this gap

By reconnecting this new instrument to her bank context, she constructs the concept as a new way of identifying problems (theme 8) and simultaneously as an improvement of her understanding of the decisions of the top management team (theme 9)

I want to show the (application of the concept) to the head of IT strategy consulting in the bank. Just to see what he would say on it. Because I think there's some points in here that have been neglected when I look at the overall IT strategy (...), and which I think are valid points. So I think (...) it would be so helpful, not just for me, but I'm sure (also) for the people that I work with (...).

So having to apply the concept to the bank (...) was really good, because some of the things that have come out (...) enable you to say it's this problem, this problem (...). So (...) now I view everything differently.

This way you better understand why you're company is doing certain things and now I know how problems can be identified. (...)

\section{The mechanisms through which ambiguity affects the construction of relevance}

The analysis revealed that in addition to the patterns described above, there are also two mechanism through which the ambiguity of academic concepts influences how practitioners construct relevance. There are two themes associated with the mechanism of expansive ambiguity. The data indicate that ambiguity can promote congruence when it gives practitioners room to interpret a concept in a way that it promotes various courses of action (theme 10) or expanding organizational contexts (theme 11).The second mechanism, restrictive ambiguity shows that ambiguous academic concepts may also restrict the possibilities of 'reconnection' discussed in the previous subsection (theme 12). Again, Appendix 2 provides representative quotes that illustrate each of these second-order themes and the related first-order concepts. 
Academic concepts are ambiguous if they allow for multiple interpretations and are associated with equivocal definitions (Astley \& Zammuto, 1992; Benders \& van Veen, 2001). Ambiguity - or 'interpretive viability' (Benders \& Bijsterfeld, 2000, p. 50) - means that the scope of interpretation is fairly wide, so practitioners may discern several different ways in which an ambiguous academic concept could be used. Because ambiguous concepts do not prescribe a particular course of action, they allow practitioners to match to these concepts a range of possible actions (theme 10). For example, the next quote indicates that the concept of issues management (Ansoff, 1980) allowed the general manager of a car manufacturer to discern multiple approaches to strategy-making and to think of several courses of action because it is considered a generalized procedure:

the concept helps me see multiple ways to do strategy, so, in that sense, [it is relevant] to what I'm doing and [to what other colleagues] are doing.

Ambiguity may also relate to the range of contexts in which a concept can be used (theme 11). In that sense, ambiguous academic concepts provide abstract mechanisms that expand the range of organizational contexts to which practitioners can connect them and in which they may apply them, as the quote by a federal government consultant illustrates:

some concepts are helpful regardless of whether it's a small, medium-sized or a huge company or a government because the conceptual thinking [that these concepts provide] is so open and rudimentary, like [the concepts of] positioning, initiation and value creation. [...] these concepts relate to basic problems that are the same in all industries [such as, for example] strategy formulation and communication, top-down or bottom-up, [all these problems are] independent from industry and company specifics.

Academic concepts that provide general mechanisms, such as how to position a company in the market (Ansoff, 1980; Porter, 1997) or how to create value (Barney, 1991), pertain to a broad range of professions, organizations or industries and thus, facilitate congruence with diverse contexts. By contrast, the congruence of academic concepts that provide mechanisms for context-specific problems is likely to be perceived as limited. As the next quote shows, the 
managing director of a public broadcaster cannot match the concept of foreign direct investments (Froot, 2008) to his organizational context:

[...] as you can imagine, the concept of foreign direct investments in a media house governed by public law is not really applicable, right?

Overall, ambiguity facilitates congruence recognition between academic concepts and practitioners' contextual needs, experiences and intuitions by expanding practitioners' particular contexts and actions. Thus, it allows practitioners to make sense of it despite their concrete contexts and professional practices.

The flip side of ambiguity is that, while it allows practitioners to construct congruence with a range of contexts in which new knowledge can be applied and a range of actions they can take, at the same time it increases the complexity they have to deal with when an ambiguous concept allows for a broad range of actions. In this case ambiguous academic knowledge restricts the possibilities of reconnecting new knowledge to practitioners' contexts (theme 12). When the number of choices of meaningful actions - in other words, the complexity of action expansiveness of ambiguous concepts - overwhelms practitioners, ambiguous academic knowledge restricts the possibilities to make reconnections between the new academic knowledge and practitioners' courses of action that would allow them to legitimize, improve or innovate their existing courses of action. In this sense, ambiguous academic knowledge that allows for a range of actions that practitioners can take, restricts practitioners' relevance construction. This can be described as the mechanism of restrictive ambiguity. In the following example, the account manager of a media house indicates that because the concept of strategic issue management (Ansoff, 1980) does not prescribe a clear course of action but suggests several 'right' ways of designing organizational strategy, he cannot reconnect this concept to the process of strategy-making in his company and thus, he cannot consider it relevant. 
Certainly this concept [...] really helps mapping out something different with regard to the design of our process. [But] the problem is that [...] you have so many possibilities! Having tried to apply this concept, we realized that we [...] actually spent [too] much time discussing how it should work. You don't have any evidence that it's right. So what I was hoping to get is a procedure like when you distil schnapps: you start and at the end you have a concentrate and the machine determines the procedure. [...] But here you can turn any lever and the result is completely different. And this doesn't give you the [...] the confidence [that you have] developed an effective strategy. [...] So, in effect, strategy is about the gut feeling of a Steven Jobs or Richard Branson and [...] the rest is actually just rubbish.

This quote illustrates that ambiguous academic concepts that provide multiple courses of actions might, in fact, be considered irrelevant, because they leave too much room for interpreting how they should be applied.

\section{Discussion}

The findings of the analysis presented in the previous sections indicate that relevance requires an active construction on behalf of the practitioners in light of their particular contexts and previous knowledge. In this sense, practitioners infuse 'empty' academic concepts with meaning during the construction of relevance (Ortmann \& Salzmann, 2002; Rasche \& Seidl, 2017). This implies that the relevance of academic knowledge does not reside in the (content of) the academic concepts themselves. Rather, through congruence recognition, extension and reconnection practitioners determine the ways in which academic concepts become meaningful. Under these conditions, management researchers cannot 'achieve' relevance by producing or disseminating more relevant academic knowledge (Hambrick, 1994; Reynes, 1999). Academic knowledge is constructed as relevant on the basis of practitioners' own experiences and knowledge, and this construction processes regardless of how academic knowledge is produced or disseminated. In the following sections, I discuss the implications of these findings. 


\section{Relevance construction patterns}

First, the pattern of congruence recognition indicates that practitioners link academic knowledge to knowledge with which they are already familiar. This implies that academic knowledge that reflects or 'resonates' (Nicolai \& Dautwitz, 2010; Rasche \& Behnam, 2009; Seidl, 2007) with what practitioners already know or have experienced is more likely to be constructed as relevant. As a consequence, the relevance of academic knowledge might be more readily accessible for practitioners with lots of experience as it allows them to recognize congruence between academic knowledge. Moreover, the pattern of congruence recognition reveals the political dimension of practitioners' relevance construction by showing that they make value judgements about the practical relevance of academic knowledge mainly in light of their personal interests. In that respect, the present study examined relevance from the practitioners' perspective taking into account the 'knowledge constitutive interests' (Habermas, 1973) that practitioners pursue when they construct relevance. An interest of this type might be, e.g., legitimizing a decision or improving a practice that allows a manager to exert more power (Weingart, 1997). Because of their knowledge constitutive interests, practitioners' relevance construction tends to reproduce existing organizational structures in which they are embedded. In this sense, the pattern of congruence recognition might lead to reproducing organizational structures regardless of whether these structures are positive for and might even be detrimental to society at large (Ghoshal, 2005; Jarzabkowski, Mohrman, \& Scherer, 2010; Marti \& Scherer, 2016).

Second, complementing previous studies that argue that academic knowledge is relevant if it resonates with practitioners' particular contexts (Nicolai \& Dautwitz, 2010; Rasche \& Behnam, 2009; Rasche \& Seidl, 2017), this study shows that, in order to be constructed as relevant, academic knowledge also has to be perceived as novel. In this sense, academic knowledge that 'denies the truth of some part of [practitioners'] routinely held assumption- 
ground' (Davis, 1971: 311), that surprises (Daft \& Lewin, 1990), is interesting (Davis, 1971; Birkinshaw et al., 2016) or challenges the taken-for-granted (Gergen, 1992), is more likely to be constructed as relevant. Specifically, academic knowledge that provides practitioners with new instruments, constructs or means of scientific framing that extend their knowledge is likely to be perceived as relevant, whereas if it lacks the element of novelty, it will most likely be ignored or dismissed. The pattern of extending thus proves helpful in explaining why academic knowledge is constructed as irrelevant even if it resonates with practitioners' knowledge or contexts.

Interestingly, practitioners might be unable to reconnect academic knowledge that is radically new with established knowledge. In other words, reconnection relates new to existing knowledge and helps establish a context in which practitioners can make sense of the new knowledge. Thus, academic knowledge has to combine 'novelty and continuity' (McKinley et al., 1999, p. 637) in order to be constructed as relevant. Academic concepts should be novel enough to extend the practitioners' previous knowledge, without straying so far from existing practical or lay wisdom that practitioners cannot connect them to their practical problems and experiences. Academic knowledge that is either so novel that it does not reflect anything familiar or so familiar that it does not add anything new will be rejected as irrelevant.

The argument that academic knowledge must strike a balance between novelty and continuity provides insights into how scholars could produce knowledge that practitioners will perceive as relevant. First, the findings of inductive (and therefore qualitative) research are more likely to resonate with managers as this kind of academic reasoning gets closer to the phenomenon as experienced by the subjects themselves (Starkey \& Madan, 2001; Van de Ven \& Johnson, 2006; Birkinshaw et al., 2016). Thus, inductive research might facilitate congruence and reconnection with practitioners' knowledge and contexts. Secondly, research findings that resonate with practitioners should also be novel, which could be facilitated by editorial 
policies. Even though existing policies typically support novelty, they lend less support for the topicality of research findings. Often, a lengthy publication process impedes topicality which might result in academic findings that are at odds with current societal issues (Kieser \& Leiner, 2009; Whiteman, Walker \& Perego, 2013). Thirdly, balancing novelty and continuity does not imply that practitioners should get involved in the development of academic knowledge. On the contrary, researchers need autonomy and independence from management practice to produce knowledge that extends the practitioners' existing knowledge (Whitley, 1984). Additionally, striking a balance between novelty and continuity might be facilitated by producing ambiguous academic knowledge, which will be discussed in the next section.

\section{The ambiguous role of ambiguity}

Examining the practitioners' perspective on the practical relevance of academic knowledge revealed also two mechanisms that are related to the role of ambiguity in constructing relevance: the mechanism of expansive ambiguity and the mechanism of restrictive ambiguity. The first mechanism indicates that practitioners may find it easier to identify links between ambiguous academic concepts and their context if they perceive these concepts as context expansive, i.e. if they appeal to a broad range of organisational contexts. Context expansiveness implies that academic knowledge that is context-bound and addresses real-life problems (Kemen \& Bansal, 2002; Lewin \& Greenwood; Reason, 2006), restricts the possibility of being matched to a multiplicity of contexts and thus the chance of being relevant. However, context expansiveness does not imply that management research should offer standardized solutions (Whitley, 1988; Nicolai \& Seidl, 2010). Rather, context expansiveness facilitates the construction of relevance by allowing practitioners to construct particular, contextual solutions themselves. The mechanism of expansive ambiguity also indicates that practitioners may find it easier to identify links between ambiguous academic concepts and their context if they are action expansive, i.e. they allow practitioners to match it 
to a range of possible actions. To increase its scope, academic knowledge has to be context and action expansive.

The second mechanism indicates that even though the action expansiveness of ambiguous academic knowledge facilitates the construction of relevance, it also increases the complexity of making a connection to a meaningful course of action. As action expansiveness leaves the particular usage of academic concepts open (Benders \& van Bijsterveld, 2000), it does not prescribe which courses of action to follow or to address directly 'how to's' and 'when to's' (Bacharach, 1989). In this case, the breadth of the range of possible actions may overwhelm practitioners and thus obscure the reconnection to a course of action that is most meaningful and relevant to them. Consequently, when action expansiveness complicates the way in which practitioners reconnect ambiguous academic knowledge to their context (Starkey \& Madan, 2001; Bartunek, Gordon, \& Weathersby, 1983) they will construct this knowledge as irrelevant. This is particularly the case if practitioners perceive academic knowledge as new constructs that do not prescribe courses of action (Bartunek et al., 2011; Nicolai \& Seidl, 2010). By contrast, academic knowledge that 'influences what courses of action we select in particular decision situations' (Nicolai \& Seidl, 2010: 1263) reduces complexity by excluding alternative actions and suggesting a single 'best way', but at the same time it also hinders congruence recognition and thus the construction of relevance. However, as Mintzberg (2005, p. 381) states, 'managers can and should use dialogue to find answers to their questions instead of expecting readymade prescriptions [that exclude alternative actions]. Prescriptions are most of all the job of practitioners themselves as they face an issue within a context'. Nevertheless, the mechanism of restrictive ambiguity shows that ambiguous academic knowledge that is action expansive might restrict practitioners' construction of relevance.

Previous studies on this topic implicitly assume that the more ambiguous the academic knowledge, the greater the opportunity for practitioners to make sense of academic 
knowledge in light of their particular contexts and knowledge (Astley \& Zammuto, 1992; Rasche \& Behnam, 2009; Seidl, 2007). In contrast, this study has shown through the mechanism of expansive ambiguity and the mechanism of restrictive ambiguity that the role of ambiguity is itself ambiguous. Ambiguous academic knowledge may facilitate but may also restrict practitioners' construction of relevance. Thus, my study shows that there are limits to the role of ambiguity in facilitating the practitioners' construction of relevance, in particular if ambiguous academic knowledge is action expansive.

\section{Limitations and future research}

The findings of this study are based on a qualitative investigation into how practitioners construct relevance. As a result, this paper has certain limitations, which at the same time open up areas for future research. One limitation is that the analysis relied on data from the context of executive management education. Given that the way in which academic knowledge is taught and discussed in a specific academic setting may influence how students construct it, it is possible that the context of executive education may have influenced the way in which the practitioners in the sample perceived and evaluated this knowledge as relevant or irrelevant. Future studies could investigate how different teaching styles might influence practitioners' construction of relevance.

The fact that this study relied mainly on interviews to examine how practitioners construct relevance may pose a second limitation. A typical criticism of qualitative methods of interviewing is that they create in interviewees the 'social desire' to respond to the interviewer's needs (Rubin \& Rubin, 2011). In the case of this study, it is possible that the interviewees may have been prompted to reflect on the ways in which academic knowledge is relevant to them. In addition, the interviews were conducted at a particular point in time, during or shortly after they attended the courses. However, practitioners might construct relevance differently if they were asked about the relevance of the academic concepts several 
years after having attended management courses. Thus, future research could draw on longitudinal data to examine how practitioners construct relevance.

Another topic that could be further explored is how the way in which practitioners construct relevance affects the reproduction and modification of organizational structures and practices. For example, the tendency of practitioners to regard as relevant those concepts that they recognise as congruent with their context points to a tendency to reproduce the organizational structures that shape and are part of this context and raises the question of how this tendency might interfere with change. Researchers could investigate this topic particularly in light of critical management studies by exploring how the ways in which practitioners construct relevance contribute to the reproduction of the dominant power structures within organizational contexts.

\section{Conclusion and contributions to the literature}

Although the literature on practical relevance emphasizes that practice itself ultimately determines whether academic knowledge is practically relevant (e.g. Kieser, Nicolai, \& Seidl, 2015), there is little research on how practitioners construct relevance. Based on the analysis of practitioners' accounts of the relevance of various academic concepts, this study identified the patterns that explain practitioners' relevance construction and the ambiguity mechanisms that mediate this construction. The study provides a novel understanding of relevance from the perspective of practitioners and contributes to the literature on practical relevance in the two main ways. First, the study extends existing literature by showing that besides resonating with practitioners' context and interest, academic knowledge also has to be novel to be considered relevant. Second, in contrast to the assumption that ambiguity of academic knowledge is facilitative for the construction of relevance, this study shows that ambiguous academic knowledge restricts relevance construction when it expands the range of possible actions to a degree that practitioners find overwhelming. 


\section{NOTES}

${ }^{i}$ These first-order categories do not necessarily incorporate the language of organizational actors as they intend to provide simple, descriptive labels for commonly described patterns of relevance construction in the data and thus represent an initial aggregation of the data (Maitlis \& Lawrence, 2007; Van Maanen, 1979). 


\section{References}

Adler, N. J., \& Harzing, A.-W. 2009. When knowledge wins: Transcending the sense and nonsense of academic rankings. Academy of Management Learning \& Education, 8(1): $72-95$.

Afuah, A. 1998. Models of innovation. Innovation Management New York: Oxford University Press.

Anderson, R. D. 2002. Reforming science teaching: What research says about inquiry. Journal of science teacher education, 13(1): 1-12.

Ansoff, H. 1965. Corporate Strategy. New York.

Ansoff, H. I. 1980. Strategic issue management. Strategic Management Journal, 1(2): 131148.

Astley, W. Graham, \& Zammuto, R. F. 1992. Organization Science, Managers, and Language Games. Organization Science, 3(4): 443-460.

Baldridge, D. C., Floyd, S. W., \& Markóczy, L. 2004. Are managers from Mars and academicians from Venus? Toward an understanding of the relationship between academic quality and practical relevance. Strategic Management Journal, 25(11): 10631074.

Bansal, P., Bertels, S., Ewart, T., MacConnachie, P., \& O’Brien, J. 2012. Bridging the research-practice gap. The Academy of Management Perspectives, 26(1): 73-92.

Barney, J. 1991. Firm resources and sustained competitive advantage. Journal of Management, 17(1): 99-120.

Baron, D. P. 1995. The nonmarket strategy system. Sloan Management Review, 37: 73.

Bartunek, J. M., Gordon, J. R., \& Weathersby, R. P. 1983. Developing "complicated" understanding in administrators. Academy of management Review, 8(2): 273-284.

Bartunek, J. M., \& Rynes, S. L. 2014. Academics and Practitioners Are Alike and Unlike: The Paradoxes of Academic-Practitioner Relationships. Journal of Management.

Bebchuk, L. A., \& Fried, J. M. 2006. Pay without Performance Overview of the issues. The Academy of Management Perspectives, 20(1): 5-24.

Benders, J., \& van Bijsterveld, M. 2000. Leaning on lean: the reception of a management fashion in Germany. New Technology, Work and Employment, 15(1): 50-64.

Beyer, J. M. 1997. Research utilization bridging a cultural gap between communities. Journal of Management Inquiry, 6(1): 17-22.

Beyer, J. M., \& Trice, H. M. 1982. The utilization process: A conceptual framework and synthesis of empirical findings. Administrative Science Quarterly: 591-622.

Bower, J. L. 2008. The teaching of strategy: from general manager to analyst and back again? Journal of Management Inquiry(17): 269-275.

Brown, J. S., \& Duguid, P. 1991. Organizational learning and communities-of-practice: Toward a unified view of working, learning, and innovation. Organization Science, 2(1): $40-57$.

Burke, L. A., \& Rau, B. 2010. The research-teaching gap in management. Academy of Management Learning \& Education, 9(1): 132-143. 
Cohen, W. M., \& Levinthal, D. A. 1990. Absorptive capacity: a new perspective on learning and innovation. Administrative Science Quarterly: 128-152.

Conger, J. A., \& Xin, K. 2000. Executive education in the 21st century. Journal of Management Education, 24(1): 73-101.

Corbin, J., \& Strauss, A. 2014. Basics of qualitative research: Techniques and procedures for developing grounded theory: SAGE Publications.

Corburn, J. 2005. Street science: Community knowledge and environmental health justice: MIT Press Cambridge.

Corley, K. G., \& Gioia, D. A. 2011. Building theory about theory building: what constitutes a theoretical contribution? Academy of management Review, 36(1): 12-32.

Davis, M. S. 1986. 'That's classic!'The phenomenology and rhetoric of successful social theories. Philosophy of the Social Sciences, 16(3): 285-301.

De Geus, Arie P. 1988. Planning as learning.

Denis, J.-L., Dompierre, G., Langley, A., \& Rouleau, L. 2011. Escalating indecision: Between reification and strategic ambiguity. Organization Science, 22(1): 225-244.

Denzin, N. K., \& Lincoln, Y. S. 2008. Collecting and interpreting qualitative materials: Sage.

Eisenhardt, K. M. 1989. Building theories from case study research. Academy of management Review, 14(4): 532-550.

Eisenhardt, K. M. 1991. Better stories and better constructs: The case for rigor and comparative logic. Academy of management Review, 16(3): 620-627.

Eisenhardt, K. M., \& Graebner, M. E. 2007. Theory building from cases: Opportunities and challenges. Academy of Management Journal, 50(1): 25-32.

Fligstein, N. 1996. Markets as politics: A political-cultural approach to market institutions. American sociological review: 656-673.

Fournier, V., \& C. Grey. At the critical moment: Conditions and prospects for critical management studies. Human relations 53.1 (2000): 7-32.

Froot, K. A. 2008. Foreign direct investment: University of Chicago Press.

Geertz, C. 1983. Local knowledge: Further essays in interpretive anthropology. New York: Basic Books.

Geroski, P. 2003. The evolution of new markets: Oxford University Press.

Ghemawat, P. 2007. Redefining global strategy. Boston: Harvard Business School Publishing: 40-64.

Gibbons, M., Limoges, C., Nowotny, H., Schwartzman, S., Scott, P., \& Trow, M. 1994. The new production of knowledge: The dynamics of science and research in contemporary societies: Sage.

Gioia, D. A., Corley, K. G., \& Hamilton, A. L. 2013. Seeking qualitative rigor in inductive research notes on the Gioia methodology. Organizational Research Methods, 16(1): 1531.

Gioia, D. A., \& Thomas, J. B. 1996. Identity, image, and issue interpretation: Sensemaking during strategic change in academia. Administrative Science Quarterly: 370-403. 
Gopinath, C., \& Hoffman, R. C. 1995. The Relevance of Strategy Research: Practitioner and Academic Viewpoints*. Journal of Management Studies, 32(5): 575-594.

Granovetter, M. S. 1973. The strength of weak ties. American journal of sociology: 13601380.

Grant, R. 2008. Why strategy teaching should be theory based. Journal of Management Inquiry(17): 276-281.

Greenwood, R., Suddaby, R., \& Hinings, C. R. 2002. Theorizing change: The role of professional associations in the transformation of institutionalized fields. Academy of Management Journal, 45(1): 58-80.

Habermas, J. A postscript to knowledge and human interests. Philosophy of the Social Sciences 3.2 (1973): 157-189.

Hambrick, D. C. 1994. What if the Academy actually mattered? Academy of management Review, 19(1): 11-16.

Hill, J., \& Houghton, P. 2001. A reflection on competency-based education: Comments from Europe. Journal of Management Education, 25(2): 146-166.

Hinings, C. R., \& Greenwood, R. 2002. Disconnects and consequences in organization theory? Administrative Science Quarterly: 411-421.

Huberman, A. M., \& Miles, M. B. 2002. The qualitative researcher's companion. Thousand Oaks.

Huff, A. S., \& Huff, J. O. 2001. Re-focusing the business school agenda. British Journal of Management, 12(s1): S49-S54.

Jarzabkowski, P., \& Wilson, D. C. 2006. Actionable Strategy Knowledge:: A Practice Perspective. European Management Journal, 24(5): 348-367.

Jarzabkowski, P., S.A. Mohrman, \& A.G. Scherer. Organization studies as applied science: The generation and use of academic knowledge about organizations introduction to the special issue. Organization studies 31.9-10 (2010): 1189-1207.

Kieser, A., \& Leiner, L. 2009. Why the rigour-relevance gap in management research is unbridgeable. Journal of Management Studies, 46(3): 516-533.

Kim, W. C., \& Mauborgne, R. A. 1995. A procedural justice model of strategic decision making: Strategy content implications in the multinational. Organization Science, 6(1): 44-61.

Knorr-Cetina, K. D. 1977. Policymakers' use of social science knowledge: symbolic or instrumental?

Langley, A. 1999. Strategies for theorizing from process data. Academy of management Review, 24(4): 691-710.

Langley, A., \& Abdallah, C. 2011. Templates and turns in qualitative studies of strategy and management. Research methodology in strategy and management, 6: 201-235.

Langley, A., Smallman, C., Tsoukas, H., \& Van de Ven, Andrew H. 2013. Process studies of change in organization and management: unveiling temporality, activity, and flow. Academy of Management Journal, 56(1): 1-13.

Lex Donaldson. 2001. The contingency theory of organizations: Sage. 
MacLean, D., MacIntosh, R., \& Grant, S. 2002. Mode 2 management research. British Journal of Management, 13(3): 189-207.

Maitlis, S. 2005. The social processes of organizational sensemaking. Academy of Management Journal, 48(1): 21-49.

March, J. G. 2006. Rationality, foolishness, and adaptive intelligence. Strategic Management Journal, 27(3): 201-214.

Matthew B. Miles, \& A. Michael Huberman. 1994. Qualitative data analysis: An expanded sourcebook: Sage.

Minsky, M. 1988. Society of mind: Simon and Schuster.

Mintzberg, H. 2003. The strategy process: concepts, contexts, cases: Pearson Education.

Mintzberg, H. 2005. Developing theory about the development of theory. Great minds in management: The process of theory development: $355-372$.

Nicolai, A., \& Seidl, D. 2010. That's relevant! Different forms of practical relevance in management science. Organization Studies, 31(9-10): 1257-1285.

Nicolai, A. T., \& Dautwiz, J. M. 2010. Fuzziness in action: what consequences has the linguistic ambiguity of the core competence concept for organizational usage? British Journal of Management, 21(4): 874-888.

Ortmann, G. 1995. Formen der Produktion: Organisation und Rekursivität: Westdeutscher Verlag Opladen.

Ortmann, G. 2004. Als Ob: Fiktionen und Organisationen: Springer-Verlag.

Ortmann, G., \& Salzman, H. 2002. Stumbling giants: The emptiness, fullness, and recursiveness of strategic management. Soziale Systeme: Zeitschrift für Soziologische Theorie, 8(2): 205-230.

Oviatt, B. M., \& Miller, W. D. 1989. Irrelevance, Intransigence, and Business Professors. The Academy of Management Executives(3): 304-312.

Pandza, K., \& Thorpe, R. 2010. Management as design, but what kind of design? An appraisal of the design science analogy for management. British Journal of Management, 21(1): 171-186.

Patton, M. Q. 1990. Qualitative evaluation and research methods: SAGE Publications, inc.

Patton, M. Q. 2005. Qualitative research: Wiley Online Library.

Pelz, D. C. 1978. Some expanded perspectives on use of social science in public policy. Major social issues: A multidisciplinary view: 346-357.

Polanyi, M., \& Prosch, H. 1977. Meaning: University of Chicago Press.

Porter, M. E. 1997. Competitive strategy. Measuring Business Excellence, 1(2): 12-17.

Powell, T. C., Lovallo, D., \& Caringal, C. 2006. Causal ambiguity, management perception, and firm performance. Academy of management Review, 31(1): 175-196.

Prahalad, C. K., \& Hamel, G. 1990. The core competence of the corporation. Boston (Ma), 1990: 235-256.

Rasche, A., \& Behnam, M. 2009. As If it Were Relevant A Systems Theoretical Perspective on the Relation Between Science and Practice. Journal of Management Inquiry, 18(3): 243-255. 
Reason, P. 2006. Choice and quality in action research practice. Journal of Management Inquiry, 15(2): 187-203.

Reitzig, M., \& Puranam, P. 2009. Value appropriation as an organizational capability: The case of IP protection through patents. Strategic Management Journal, 30(7): 765-789.

Robert French, \& Grey, C. 1996. Rethinking management education: Sage.

Rouleau, L. 2005. Micro-Practices of Strategic Sensemaking and Sensegiving: How Middle Managers Interpret and Sell Change Every Day*. Journal of Management Studies, 42(7): $1413-1441$.

Rousseau, D. M. 2012. Designing a Better Business School: Channelling Herbert Simon, Addressing the Critics, and Developing Actionable Knowledge for Professionalizing Managers. Journal of Management Studies, 49(3): 600-618.

Rubin, H. J., \& I.S. Rubin. Qualitative interviewing: The art of hearing data. Sage, 2011.

Rynes, S. L., Bartunek, J. M., \& Daft, R. L. 2001. Across the great divide: Knowledge creation and transfer between practitioners and academics. Academy of Management Journal, 44(2): 340-355.

Sandelands, L., \& Drazin, R. 1989. On the language of organization theory. Organization Studies, 10(4): 457-477.

Santos, F. M., \& Eisenhardt, K. M. 2009. Constructing markets and shaping boundaries: Entrepreneurial power in nascent fields. Academy of Management Journal, 52(4): 643671.

Scherer, A. G. 2009. Critical Theory and its Contribution to Critical Management Studies. In M. Alvesson, H. Willmott \& T. Bridgman (Eds.), The Oxford Handbook of Critical Management Studies: 29-51. Oxford: Oxford University Press.

Schumpeter, J. A. 1950. Capitalism, Socialism, and Democracy. 3d Ed: New York, Harper $[1962$.

Seidl, D. 2007. General strategy concepts and the ecology of strategy discourses: A systemicdiscursive perspective. Organization Studies, 28(2): 197-218.

Seidl, D. 2009. Productive misunderstandings between organisation science and organisation practice: the science-practice relation from the perspective of Niklas Luhmann's theory of autopoietic systems. Autopoiesis in Organization Theory and Practice, Bingley, UK: $133-148$.

Silverman, D. 2006. Interpreting qualitative data: Methods for analyzing talk, text and interaction: Sage.

Simon, H. A. 1978. Information-processing theory of human problem solving. Handbook of learning and cognitive processes, 5: 271-295.

Starkey, K., \& Madan, P. 2001. Bridging the relevance gap: aligning stakeholders in the future of management research. British Journal of Management, 12(s1): S3-S26.

Tinsley, H. E. A., \& Weiss, D. J. 2000. Interrater reliability and agreement. Handbook of applied multivariate statistics and mathematical modeling: 95-124.

Tourish, D. 2013. 'Evidence Based Management', or 'Evidence Oriented Organizing'? A critical realist perspective. Organization, 20(2): 173-192. 
Tushman, M. L., O'Reillly, C. A., Fenollosa, A., Kleinbaum, A. M., \& McGrath, D. 2007. Relevance and rigor: executive education as a lever in shaping practice and research. Academy of Management Learning and Education(6): 345-362.

Vaara, E., \& Faÿ, E. 2012. Reproduction and Change on the Global Scale: A Bourdieusian Perspective on Management Education. Journal of Management Studies, 49(6): 10231051.

Van de Ven, Andrew H, \& Johnson, P. E. 2006. Knowledge for theory and practice. Academy of management Review, 31(4): 802-821.

Whitley, R. 1984. The scientific status of management research as a practically-oriented social science. Journal of Management Studies, 21(4): 369-390.

Willmott, H. 2003. Organization theory as critical science? Forms of analysis and new organizational forms. In H. Tsoukas (Ed.), The Oxford handbook of organization theory. Oxford: Oxford University Press.

Yanow, D. 2012. Organizational ethnography between toolbox and world-making. Journal of Organizational Ethnography, 1(1): 31-42.

Yin, R. K. 2013. Case study research: Design and methods: SAGE Publications. 
TABLE I

Overview of Executive Courses

\begin{tabular}{|c|c|c|c|c|c|c|}
\hline Course & Accreditations & Requirements & Duration & Teaching method & Number of participants & Course content \\
\hline 1 & $\begin{array}{l}\text { EQUIS } \\
\text { AACSB } \\
\text { FIBA }\end{array}$ & $\begin{array}{l}\text { Bachelor degree plus } \\
\text { either } \\
5 \text { years managerial } \\
\text { experience or } 3 \text { years } \\
\text { leadership experience }\end{array}$ & $\begin{array}{l}10 \text { days } \\
\text { (10 hours } \\
\text { per day) }\end{array}$ & $\begin{array}{l}\text { - Focus on case } \\
\text { studies } \\
\text { - In addition: } \\
\text { lectures, guest } \\
\text { speakers }\end{array}$ & 48 & $\begin{array}{l}\text { - Competitive advantage } \\
\text { - Positioning } \\
\text { - Value creation } \\
\text { - Corporate restructuring } \\
\text { - Change management }\end{array}$ \\
\hline 2 & $\begin{array}{l}\text { EQUIS } \\
\text { AACSB } \\
\text { QAA }\end{array}$ & $\begin{array}{l}\text { University degree plus } \\
6 \text { years managerial } \\
\text { experience }\end{array}$ & $\begin{array}{l}3 \text { days } \\
\text { ( } 8 \text { hours } \\
\text { per day) }\end{array}$ & $\begin{array}{l}\text { - Focus on group } \\
\text { presentations } \\
\text { - In addition: } \\
\text { lectures }\end{array}$ & 28 & $\begin{array}{l}\text { - Competitive advantage } \\
\text { - Analysing markets } \\
\text { - Corporate boundaries } \\
\text { - Value creation } \\
\text { - Strategic capabilities }\end{array}$ \\
\hline 3 & $\begin{array}{l}\text { EQUIS } \\
\text { AMBA } \\
\text { AACSB }\end{array}$ & $\begin{array}{l}\text { University degree plus } \\
4 \text { years managerial } \\
\text { experience or } 7-10 \\
\text { years managerial } \\
\text { experience without a } \\
\text { university degree }\end{array}$ & $\begin{array}{l}3 \text { days } \\
\text { ( } 9 \text { hours } \\
\text { per day) }\end{array}$ & $\begin{array}{l}\text { - Focus on real-life } \\
\text { cases } \\
\text { - In addition: } \\
\text { lectures }\end{array}$ & 14 & $\begin{array}{l}\text { - Competitive advantage } \\
\text { - Goal systems } \\
\text { - Stakeholder management } \\
\text { - Strategic management issues and } \\
\text { prioritisation of issues } \\
\text { - Value creation }\end{array}$ \\
\hline 4 & $\begin{array}{l}\text { EDEXCEL } \\
\text { UKBA } \\
\text { QAA } \\
\text { BAC }\end{array}$ & $\begin{array}{l}\text { Undergraduate degree } \\
\text { or equivalent } \\
\text { professional } \\
\text { qualification plus } 5 \\
\text { years managerial }\end{array}$ & $\begin{array}{l}10 \text { days } \\
\text { ( } 4 \text { hours } \\
\text { per day) }\end{array}$ & $\begin{array}{l}\text { - Focus on lectures } \\
\text { - In addition: case } \\
\text { studies }\end{array}$ & 31 & $\begin{array}{l}\text { - Strategic capabilities } \\
\text { - Strategic management of innovation } \\
\text { - Institutional developments of nascent } \\
\text { markets } \\
\text { - Market analysis }\end{array}$ \\
\hline
\end{tabular}


TABLE II

Overview of information on practitioners

\begin{tabular}{|c|c|c|}
\hline Primary criteria & Secondary criteria & Number of practitioners \\
\hline \multirow{3}{*}{ Age group* } & $20-30$ & $13 / 53$ \\
\hline & $31-40$ & $20 / 53$ \\
\hline & $41+$ & $15 / 53$ \\
\hline \multirow{3}{*}{ Education* } & Natural sciences & $18 / 53$ \\
\hline & Social sciences & $25 / 53$ \\
\hline & Apprenticeship & $07 / 53$ \\
\hline \multirow{3}{*}{$\begin{array}{l}\text { Professional experience } \\
\text { (years) }\end{array}$} & $5-10$ & $22 / 53$ \\
\hline & $11-15$ & $17 / 53$ \\
\hline & $16+$ & $14 / 53$ \\
\hline \multirow{3}{*}{ Current position } & Lower managers & $15 / 53$ \\
\hline & Middle managers & $26 / 53$ \\
\hline & TMT/CEO & $12 / 53$ \\
\hline \multirow{2}{*}{ Type of organization } & $\begin{array}{l}\text { For profit } \\
\text { (regional, national and international) }\end{array}$ & $41 / 53$ \\
\hline & $\begin{array}{l}\text { Non-profit } \\
\text { (regional, national and international) }\end{array}$ & $12 / 53$ \\
\hline \multirow{5}{*}{ Nationality } & Europe & $41 / 53$ \\
\hline & North America & $13 / 53$ \\
\hline & Africa & $4 / 53$ \\
\hline & Asia & $3 / 53$ \\
\hline & Australia & $2 / 53$ \\
\hline
\end{tabular}

* Note that some practitioners did not provide information on their age or education

\section{TABLE III}

Overview of Collected Data

\begin{tabular}{lcccc}
\hline & Main data & \multicolumn{2}{c}{ Secondary data } & \\
\cline { 2 - 5 } & $\begin{array}{c}\text { Number of } \\
\text { interviews with } \\
\text { practitioners }\end{array}$ & $\begin{array}{c}\text { Number of } \\
\text { document } \\
\text { pages }\end{array}$ & $\begin{array}{c}\text { Hours of } \\
\text { observation }\end{array}$ & $\begin{array}{c}\text { Number of } \\
\text { photographs } \\
\text { and videos }\end{array}$ \\
\hline Course 1 & 17 & 600 & 100 & 20 \\
\hline Course 2 & 11 & 500 & 30 & 12 \\
\hline Course 3 & 13 & 600 & 30 & 35 \\
\hline Course 4 & 12 & 300 & 30 & 17 \\
\hline Total & 53 & $\mathbf{2 0 0 0}$ & $\mathbf{1 9 0}$ & $\mathbf{8 4}$
\end{tabular}


FIGURE 1

Data structure

First-Order Concepts

- Practitioners perceive new knowledge as source of potential solutions to organizational problems

- Practitioners perceive fit between new knowledge and organizational needs

- Practitioners perceive fit between new knowledge and personal needs

- Practitioners relate new knowledge to their experiences

- New knowledge reveals new approaches and new processes

- Practitioners relate new knowledge to their intuitions

- New knowledge reveals new approaches to handling an issue

- Academic knowledge points to new procedures

- Academic knowledge is perceived as new systematics for ordering

- Academic knowledge is perceived as new tool

- Academic knowledge points to new concepts

- Academic knowledge points to new causal relations

- Academic knowledge provides new terminology for argumentation

- Academic knowledge provides new terminology for actions
Second-Order

Themes
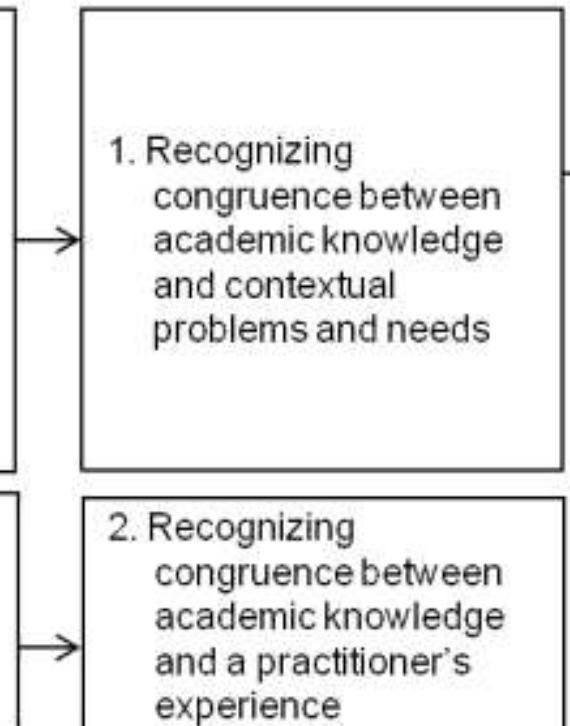

2. Recognizing congruence between academic knowledge and a practitioner's experience
3. Recognizing congruence between academic knowledge and a practitioner's intuition

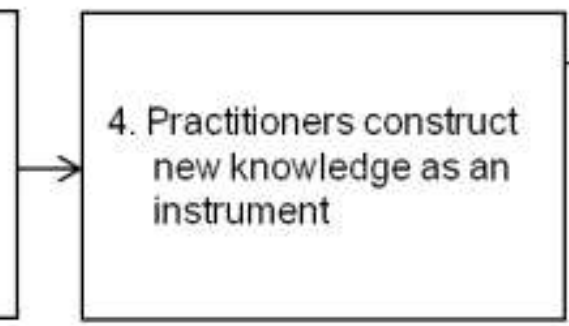

\section{Practitioners construct} new knowledge as a construct

\section{Congruence} between knowledge and a practitioner's background
Practitioner's knowledge extension 
- Academic knowledge affirms decisions and future actions

- Academic knowledge lends credibility to argumentation and actions

- Academic knowledge enhances existing professional practices

- Academic knowledge enhances existing understandings of situations or problems

- Academic knowledge points to new courses of action

- Academic knowledge enables new understandings of situations and problems

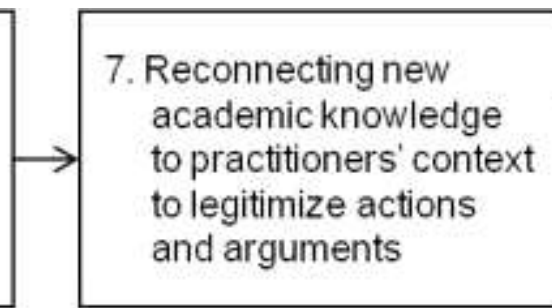

8. Reconnecting new academic knowledge to practitioners' context to improve existing practices and views

9. Reconnecting new academic knowledge to practitioners' context to come up with new ways of thinking and approachingissues
Reconnecting new academic knowledge to practitioners' background constructs relevance

- Ambiguous academic knowledge allows for multiple courses of action

- Ambiguous academic knowledge does not prescribe particular courses of action

- Ambiguous concepts widely applicable in many industries

- Ambiguous concepts widely applicable in many types of organizations

- Ambiguous concepts provide too many options, making it hard to decide on a course of action

- Ambiguous concepts do not prescribe a course of action
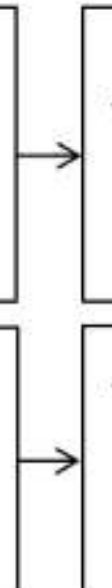

11. Ambiguous concepts expand range of contexts in which they may be applied

10. Ambiguous concepts expand range of potential action

Expansive ambiguity

12. Ambiguous concepts restrict the possibilities of reconnecting new knowledge to a context

Restrictive ambiguity 
Figure 2

Theoretical model of practitioner's relevance construction

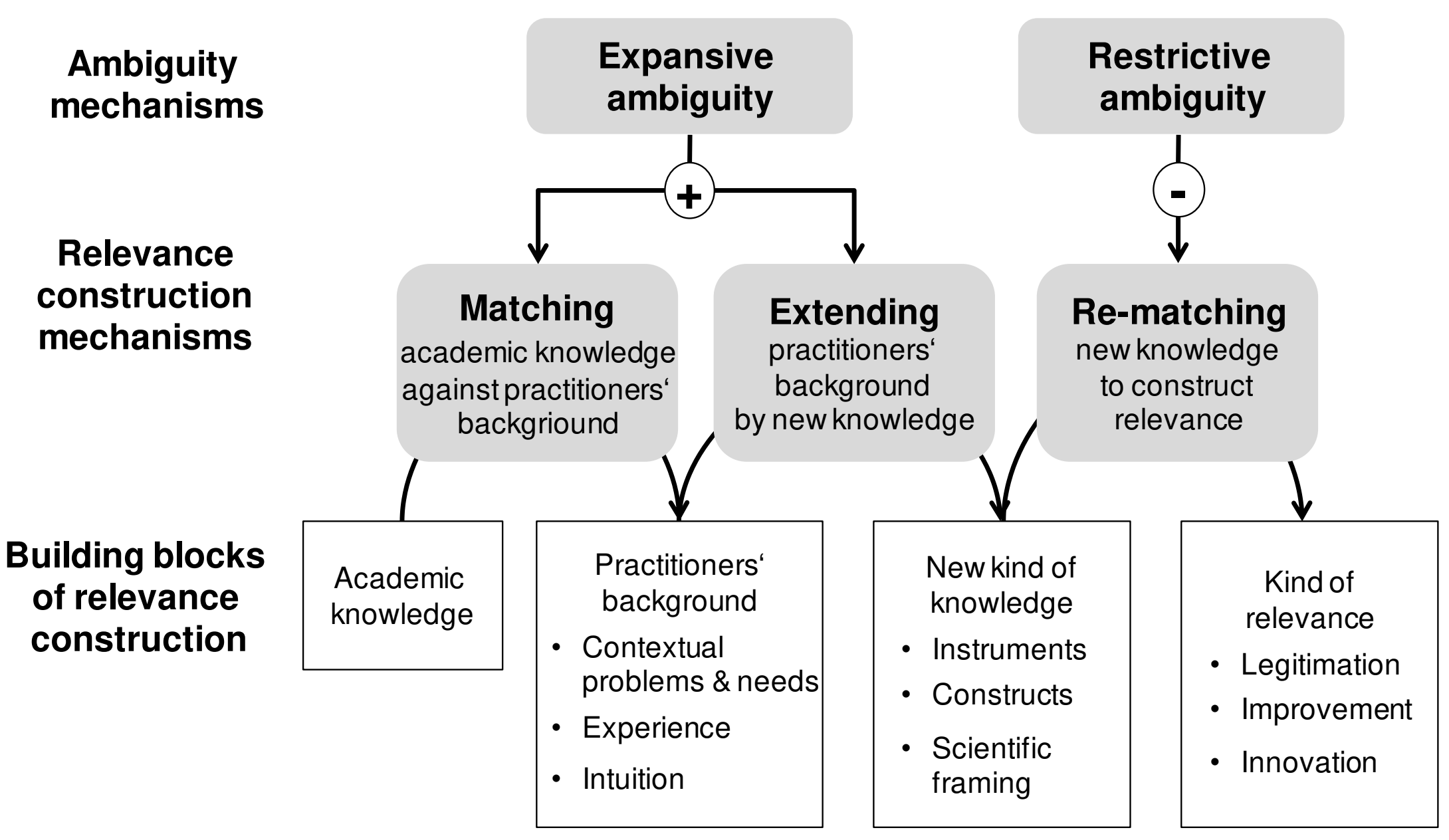




\section{Appendix 1}

Interview guideline

1. Information on the interviewee's background
a. Details on academic background
b. Details on professional experience

2. Information on the interviewee's present situation

a. Information on the organization the interviewee works for

b. Function and responsibilities

3. Expectations from and preparation for the course

4. How does the course content benefit the interviewee?

a. Examples of professional benefits

b. Examples of personal benefits

5. The interviewee describes and explains where and how the course content could be applied in practice

6. The interviewee evaluates the degree to which he/she finds the course content interesting and explains why

7. The interviewee compares the course content to that of other similar courses in terms of benefits and applicability 


\section{Appendix 2}

\section{Representative quotes that illustrate second-order themes}

\section{Theme 1: Congruence between academic knowledge and a practitioner's context}

Practitioners
perceive that a
concept provides
potential solutions to
an organizational
problem

Practitioners fit a concept to an organizational need

Practitioners fit a concept to their professional needs
1.1 [...] many times organisations are stuck with their strategy [and organizational members stick to] the framework that they have build on. [They claim] it has worked for 20 or 30 years, [so]it also should work now. It's like [...] doing the same thing over and over again. [For example] that's what Wall Street's right now is currently on, it's an insane path trying to figure out how to make money based on the old models. [...] Based on the framework I see the opportunity to actually start breaking that strategy that Wall Street has [...].(A business manager at the stock market referring to the concept of 'market institutions', discussed by Fligstein, 1996)

1.2 The public healthcare sector suffers from 'silo thinking' and it helped to see [concepts for]other organizational designs, [...] in which the structure is turned upside down. [...] The medical sector is extreme [with regard to its typical organizational structure]. We have a medical hospital, a surgical hospital, a gynaecological hospital etc., and if we would turn that [i.e. organize according to functions] we could see what connects theses hospitals or what is the same across hospitals, like in-patient and out-patient processes, administrative processes etc. (A chief physician referring to the concept of 'organizational design', discussed by Donaldson, 2001)

1.3 In the media industry [the concept of] 'positioning' is particularly important because the question is how much [financial] support channels governed by public law will get in the future and how strong they are regulated or not. [...] The channels governed by public law didn't care about positioning or finding themselves in the market in the past. Nowadays they have to care about positioning because the market is just evolving. In the past there were just public channels, so de facto there was no market. And then it was suddenly possible to watch the channels from another country [with the same language], i.e. there was an international rivalry. And then the private channels popped up and so it became really important [for the public channels] to position themselves. (A managing editor of a public service broadcaster referring to the concept of 'competitive strategy', discussed by Porter, 1997)

$1.4[\mathrm{In}]$ administration we have to care much more about positioning. We still live from hand to mouth. [...] especially in crime fighting, the question is "do we fight against Italian organized crime or against the Russian or the Chinese [organized crime] or do we fight against the motorcycle gangs? (The CEO of the federal police department referring to the concept of 'outside-in view on strategy', discussed by Ansoff, 1965; see also Porter, 1997)

1.5 I always thought we need that [strategic thinking to improve the services] for the patients but that's not my interest. The others will think of value creation and growth and so on. But if you have to work with [...] other administrative departments, you have to speak their language. You can't talk in Latin to them, like I sometimes do with my colleagues [other doctors]. (A senior physician referring to the 'resource-based view', discussed by Barney, 1991) 
Theme 2: Congruence between academic knowledge and a practitioner's experience

Practitioners relate a concept to their experience
2.1 We often [had] strategy meetings where we intuitively applied the insideout/outside-in perspective, but the framework helps do that in a more structured way and pay attention to all possible aspects. [...] So, for example, we'd usually say, these are our competences and this is the market and we will do something, but we never consciously asked ourselves: does my firm adjust to the market or does the market adjust to my firm? (A project manager at a consulting firm referring to the 'outside-in' perspective on strategy, discussed by Ansoff, 1965; see also Porter, 1997)

2.2 The point is that you realize that every strategic issue that you add will have a follow-up element. That is cause-and-effect. Often in strategy you think about an issue but then you stop and you don't think about the next steps. [The concept]provides relational and consequential thinking. (Marketing manager of a logistics company refers to the concept of 'means-ends', discussed by Simon, 1978)

2.3 I always tell people that carrying out a "lean" or "six-sigma" project [...] means [...] that I'm taking some of the tools that are in that toolbox - there are sort of classic projects where you go through one set of tools that have been linked together; but in many projects I will take individual tools, where they're applicable - and it's the same thing here; I feel that I'm being given a new set of tools that I can use and when I'm confronted with problems, then I'll be able to think about which tool is most applicable then and apply it. (A project manager at a car manufacturing company referring to the concept of 'models of innovation', discussed by Afuah, 1998)

\section{Theme 3: Congruence between academic knowledge and a practitioner's intuition}

Practitioners relate academic knowledge to their intuition
3.1 You're talking about strategic [ideas] that are more or less intuitive and common sense but you're trying to get systematic about your insights. (The general manager at a stock exchange market referring to the concept of 'strategic issue management', discussed by Ansoff, 1980)

3.2 I think it is all about understanding people [...] and although we say that we cannot put people into boxes, I would now say, you probably can. You can put them in jars and tip them in different boxes [...] and if you are able to understand that [...], then you are able to kind of manage the whole situation better. Strategy - it is all about intuitive matters, like communication; it is about people, it is about the ability [...] to structure the way forward, creating a better plan for the business; but without people, that does not work, really. (The CEO of an IT consultancy referring to the concept of 'procedural justice', discussed by Kim \& Mauborgne, 1995)

3.3 I have never developed a strategy myself [...]; intuitively all the relationships between strategic initiation, change, etc. were familiar, but to put that in a framework and show the process was new. (A project manager at an international airport referring to the concept of 'strategic issue management', discussed by Ansoff, 1980) 
Theme 4: Practitioners perceive new knowledge as an instrument

Academic concepts

reveal new

procedures
4.1 My starting point is always what has happened before, not like starting with a blank piece of paper, just saying, ok, tell me what you think about the future and the specific issues. [...] The process: going from generic issues, transforming this into strategy and then coming down to priorities, then to objectives and then into business calls and then again into corporate goals. You move from very detailed stuff to very high-level stuff and down to detail again, which I believe is very good, because the best strategists use both viewpoints and can shift from one to the other very quickly, very easily. (The HR director of a confectionery manufacturer refers to the concept of 'strategic issue management', discussed by Ansoff, 1980)

4.2 I am very dominant, and I tend to talk a lot, in case you have not noticed, [...] and so [...] the procedural justice [concept] gave us a lot: [...] learn to stop talking, learn to listen; it is vital for you to learn to listen. Especially when you are a consultant, [...] it is more important for you to talk [...] less and let other people talk. (The CEO of an IT consultancy referring to the concept of 'procedural justice', discussed by Kim \& Mauborgne, 1995)

An academic concept is perceived as a new form of systematics used for ordering ideas

4.3 I gained methodical knowledge, [i.e.] that I can [...] systematize, [...] or industrialize strategic issues, which I did before in a rather unsystematic way. [However, this concept] shows you exactly with what you start at day one, day two, day three if you develop a strategy; so it provides you with a comprehensive checklist. (A divisional director of an electric company referring to the concept of 'strategic issue management', discussed by Ansoff, 1980)

4.4 Usually when you develop strategy [...] you start somewhere - for example, with brainstorming - and then you try to put everything in an order. [But] you're not sure whether you have covered all aspects. [...] So this procedure helps [me] ask the right questions and see whether I use the right tools and the right starting point or the right information. (The CFO of an IT company referring to the concept of 'strategic issue management', discussed by Ansoff, 1980)

An academic concept

4.5 I feel that I'm being given a new set of tools that I can use and when I'm confronted with problems then I'll be able to think about which tool is most applicable and then apply it. (A project manager of a car manufacturing referring to the concept 'models of innovation', discussed by Afuah, 1998))

\section{Theme 5: Practitioners perceive new knowledge as a construct}

Academic knowledge

is perceived as a new concept
5.1 Our strategy was more customer-centred - like which products are important, do we need a spa, and what kind of spa etc. The takeaway for me is that [although] I always thought of strategy in terms of customer relations, there are other factors, like suppliers and the whole environment and the location. I've learned to pay more attention to these factors and that it would help to analyse [these issues] according to these factors. (The CEO of a hotel refers to the concept of 'competitive strategy', discussed by Porter, 1997) 
5.2 The public healthcare sector suffers from 'silo thinking' and it helped to see [concepts for]other organizational designs, [...] in which the structure is turned upside down. [...] The medical sector is extreme [with regard to its typical organizational structure]. We have a medical hospital, a surgical hospital, a gynaecological hospital etc., and if we would turn that [i.e. organize according to functions] we could see what connects theses hospitals or what is the same across hospitals, like in-patient and out-patient processes, administrative processes etc. (A chief physician referring to the concept of 'organizational design', discussed by Donaldson, 2001)

Academic knowledge reveals new causal relations
5.3 We [have] often have strategy meetings where we intuitively applied the inside-out/outside-in perspective, but the framework helps do that in a more structured way and pay attention to all possible aspects. [...] So, for example, we'd usually say, these are our competences and this is the market and we will do something, but we never consciously asked ourselves: does my firm adjust to the market or does the market adjust to my firm? (A project manager at a consulting firm referring to the 'outside-in' perspective on strategy; discussed by Ansoff, 1965; see also Porter, 1997)

5.4 The point is that you realize that every strategic issue that you add will have a follow-up element. That is cause-and-effect. Often in strategy you think about an issue but then you stop and you don't think about the next steps. So [the concept] provides relational and consequential thinking. (The strategic marketing manager of a logistics company referring to the 'meansends' concept, discussed by Simon, 1978)

\section{Theme 6: Practitioners perceive knowledge as a form of scientific framing}

Academic knowledge provides new

scientific language for arguments

Academic knowledge provides new scientific language for actions
6.1 Positioning in a market - that's always a topic in my firm. But it's not [an area] that I directly influence. However, now I know the right wording and how to articulate the positioning of our company. (The CCO of pharmaceutical company referring to the concept of 'competitive strategy', discussed by Porter, 1997)

6.2 In my firm, we are too concerned about ourselves, instead of being concerned about the customer and now I have a name for that. The 'insideout perspective is OK, but we also have to think about the environment. Thus 'outside-in' would be a necessary switch for us because new technologies change the behaviour of the consumer and this perspective (...) has not yet penetrated our work. (A marketing account manager refers to the productmarket matrix; Ansoff, 1965)

\section{Theme 7: Practitioners reconnect new academic knowledge to their context to legitimize actions and arguments}

Academic knowledge provides confirmation for decisions and future actions
7.1 [In] administration we have to care much more about positioning. We still live from hand to mouth. [...] especially in crime fighting, the question is "do we fight against Italian organized crime or against the Russian or the Chinese [organized crime] or do we fight against the motorcycle gangs?" [This] concept confirmed my thinking. [We] approached strategy differently but, overall, it was a confirmation of what we have planned so far. (The CEO of the federal police department referring to the concept of 'outside-in view on strategy', discussed by Ansoff, 1965; see also Porter, 1997) 
Academic knowledge lends credibility to arguments and actions
7.2 The concept helps you to develop a strategy in a very structured way. [This way] you can explain why you're doing things the way you're doing them all the time. (The HR director of a confectionery manufacturer referring to the concept of 'strategic issue management', discussed by Ansoff, 1980)

7.3 I have worked in several strategy projects but I've never seen these steps [described in detail] and now I know what the ideal procedure would be. That doesn't mean that I will go exactly through all steps [...] in future projects, but I will bear this process in mind; and I know how I could move or should move and with which tools; and this helps me structure my work better and also communicate or sell how I would like to realize my plan better.' (The marketing manager of an insurance company referring to the process of 'strategic issue management', discussed by Ansoff, 1980)

\section{Theme 8: Practitioners envision improvement of existing practices and views on specific issues by connecting new knowledge to their context}

Academic knowledge

enhances existing

professional practices

Academic knowledge

improves the

understanding of

situations or

problems
If I have to present something to the board of governance or to a competent audience, I can use the word 'absorptive capacity' because it allows [me to embed] my presentation into a more scientific terminology. [...] It might also improve the way I communicate with the CEO. (The COO of an international airline referring to the concept of 'absorptive capacity', discussed by Cohen and Levinthal, 1990)

8.2 So the concept [...] has been very [useful] in formulating different approaches, having more robust, well thought-through approaches as we start to form alliances with some of these very large, large companies. (The senior director of a nanotechnology company referring to 'global strategy', discussed by Ghemawat, 2007)

8.3 For example, I learned 'what is distinctive?' And that core competences rarely exist. [In my firm] everyone said 'what is your core competence?', but now I would question that and ask "do you really have a core competence?" as this is something very, very rare and special. So, you don't abuse [scientific]jargon anymore.' (The strategic marketing manager of a logistics company referring to the concept of 'core competencies', discussed by Prahalad \& Hamel, 1990)

8.4 Specifically, it was interesting for me to see, what the problems could be or with what you have to be careful. [...] That you become sensible of the problem analysis because if you're in the daily business you sometimes loose that. (The head of department of a car manufacturer referring to 'incentive systems', discussed by Bebchuk \& Fried, 2006)

\section{Theme 9: Reconnecting new academic knowledge to practitioners' context to come up with new ways of thinking and approaching issues}

Academic knowledge provides new courses for existing actions
9.1 I always thought strategy is a really big thing but now I realize that I can change something on our local level and on a small scale. We are in a relatively small industry [...]. Now I know how we should develop our strategy. (The president of the board of directors of an electric company referring to the concept of 'competitive strategy', discussed by Porter, 1997) 
Academic knowledge provides new ways of understanding a situation or problem
9.2

The concepts provided me with a lot of inputs [...]. [Particularly] the framework or the process how to develop a strategy, how to evaluate the reasons, why did it go wrong in this case and where the problem areas are. So [this concept could] help me go through the whole process and analyse our problem areas. (A government consultant referring to the concept of 'strategic issue management', discussed by Ansoff, 1980)

9.3 The takeaway for me is that [although] I always thought of strategy in terms of customer relations, there are other factors, like suppliers and the whole environment and the location. I've learned to pay more attention to these factors and [I saw] that it would help to analyse [these issues] according to these factors. (The CEO of a hotel refers to the concept of 'competitive strategy', discussed by Porter, 1997)

\section{Theme 10: Ambiguous concepts expand range of potential action}

Ambiguous academic

10.1 knowledge increases the range of possible courses of action

Ambiguous academic 10.2 knowledge does not prescribe particular courses of action
There are multiple ways to structure a strategic process and there are multiple branch-specific approaches and not everything is coloured with the same brush. I appreciate that [this concept prescribes] no definitive formula. (The chief physician of a hospital department referring to the concept of 'issues management', discussed by Ansoff, 1980)

The concept enables you to match your own process to other possibilities to design the process and how it could be done differently, so it offers you possibilities to compare your own process with the scientifically or theoretically presented processes. (An army business-unit manager referring to the concept of 'strategic issue management', discussed by Ansoff, 1980)

[This concept] shows how you methodically develop a strategy, [it is a concept] that helps you to consider your options. There is no right or wrong [way]; you have to evaluate how you would do that in the right way. ( $\mathrm{A}$ project manager of a business consultancy referring to the concept of 'strategic issue management', discussed by Ansoff, 1980)

10.3 [This concept] doesn't prescribe how it should be. [When] you're supposed to provide an answer, it doesn't say, this is what you should do. (A business manager at the stock market referring to the concept of 'market institutions', discussed by Fligstein, 1996)

\section{Theme 11: Ambiguous concepts expand contexts}

Ambiguous concepts
widely applicable in
many industries
Ambiguous concepts
widely applicable in
many types of
organizations

Ambiguous concepts

11.1

The concept on creative destruction (...) could be applied to all kind of industries. (The head of department of a bank referring to the concept of 'creative destruction', discussed by Schumpeter, 1950)

11.2 (...) I work in an SME. However some concepts are very focused on strategies of large corporations, which is different from how a SME operates. There are two realities: there are strategies for large corporations in a large global economy and the strategies of niches players, like my corporations. And those realities are very different. (...) If you take positioning and analyse where you are in a Porter analysis, (...) that is also valid for a SME. I would say that this concept is interesting for every company, whether it's big or small. (Head of department of a family business referring to the concept of 'outside-in view on strategy', discussed by Ansoff, 1965 and Porter, 1997) 
11.3 My experience is that it's not true that we do it that quickly. So I'm struggling to agree with that. Because in my company, I know what will happen: The moment someone opens the mouth and says something, you have eight other people jump into it. So I struggle to see this procedural justice happening in practice. (...) I see it as a Nordic thing, like that's the way they probably do it in Norway, where you go around the table, you share a voice, everyone says what they think, but then you still do what the boss says. (The $\mathrm{HR}$ director of a confectionery manufacturer referring to the concept of 'procedural justice', discussed by Kim and Mauborgne, 1995)

Theme 12: Ambiguous concepts restrict the possibilities of reconnecting new knowledge to a context

Ambiguous concepts provide too many options

Ambiguous concepts do not prescribe a course of action
12.1 The methods, like issue management (...) show that you have several options to be able to structure or formalize certain things. Because of that it's difficult to develop strategic issues as you have the feeling that we should actually go in this direction and in this direction. So having these templates do not help deciding what I should in my case. (The CEO of an electric company referring to the concept of 'strategic issue management', discussed by Ansoff, 1980)

12.2 I've learned to proceed analytically if I'm concerned about the positioning e.g. But a synthesis of all possibilities is hardly possible. So I'm struggling to make decisions based on this and find solutions for my company. (A business unit manager of the army referring to the concept of 'outside-in view on strategy, discussed by Ansoff, 1965 and Porter, 1997)

12.3 I would have thought that in strategy there are more rules concerning do's and don'ts but I see that strategy work is very detailed and that you have to question everything a thousand times from different angles to get as many options as possible. But then it's not clear how to make a right decision at the end. And I would be curious to know how you funnel the right decision from those options. (The CEO of a logistics company refers to the concept of 'issue management', discussed by Ansoff, 1980)

* Note that some concepts have been renamed by labels of more general concepts on the same topic to ensure compliance with the confidentiality agreement 